\title{
LETTERS
}

\section{It's not just the snow; it's also the cold}

Our group found the CMAJ article by Auger and colleagues very interesting. ${ }^{1}$

We performed a retrospective analysis of all ST-segment elevation myocardial infarction (STEMI) patients between 2009-2014 who presented to St. Boniface Hospital in Winnipeg, Manitoba. ${ }^{2}$ Temperature and snowfall were collected from Environment Canada. Negative binomial regression was used to identify the relationship between weather and STEMI. We examined daily high, low and average temperature on the same day, previous day and two days prior. Daily snowfall was analyzed similarly.

Over the six-year study period, there were 1817 STEMIs. Daily high was the strongest predictor of STEMI. The average STEMI rate has a statistically significant linear trend across temperature $(p<$ $0.001)$. Extreme high temperatures $\left(>30^{\circ} \mathrm{C}\right)$ were not associated with higher rates of STEMI.

With every $10^{\circ} \mathrm{C}$ decrease in daily high, the risk of STEMI increased by $5 \%$. With multivariable analysis, daily high (relative risk [RR] 1.05, 95\% confidence interval [Cl] 1.02$1.09, p=0.005)$ and any snowfall occurring the day prior (RR 1.14, 95\% Cl 0.99-1.32, $p=$ $0.075)$ remained predictive of STEMI rate.

We found that daily high temperature and previous day snowfall were associated with increased risk of STEMI, the most serious type of myocardial infarction. Auger and colleagues studied the effect of snowfall on risk of hospital admission and death related to myocardial infarction, ${ }^{1}$ while we studied the risk of STEMI. ${ }^{2}$ Despite a different climate and study population, both studies showed increased risk of myocardial infarction with previous day snowfall.

Increased public awareness and/or reallocation of health care resources should be considered to respond to predictable seasonal increased incidence of STEMI.

\section{Shuangbo Liu MD}

Section of Cardiology, Department of Internal Medicine, Max Rady College of Medicine, Rady Faculty of Health Sciences, University of Manitoba, Winnipeg, Man.

\section{Robin A. Ducas MD}

Section of Cardiology, Department of Internal Medicine, Max Rady College of Medicine, Rady Faculty of Health Sciences, University of Manitoba, Winnipeg, Man.

\section{Brett Hiebert MSc}

Cardiac Sciences Program, St. Boniface Hospital, University of Manitoba,

Winnipeg, Man.

\section{Lillian Koley RN}

Cardiac Sciences Program, St. Boniface

Hospital, University of Manitoba,

Winnipeg, Man.

\section{Roger K. Philipp MD}

Royal Columbian Hospital, New

Westminister, BC

\section{James W. Tam MD}

Section of Cardiology, Department of Internal Medicine, Max Rady College of Medicine, Rady Faculty of Health Sciences, University of Manitoba, Winnipeg, Man.

- Cite as: CMAJ 2017 April 10;189:E546. doi: $10.1503 / \mathrm{cmaj} .732931$

\section{References}

1. Auger N, Potter BJ, Smargiassi A, et al. Association between quantity and duration of snowfall and risk of myocardial infarction. CMAJ 2017; 189:E235-42.

2. Liu S, Ducas R, Hiebert B, et al. How cold is too cold: the effect of seasonal temperature variation on risk of STEMI. Eur Heart J 2015;36(Suppl 1):709-10.

Competing Interests: None declared. 